\title{
The Development of L-phase Colonies of Neisseria gonorrhoeae
}

\author{
By I. GEARY AND SHEENA A. WAITKINS* \\ Department of Medical Microbiology, \\ The University of Sheffield Medical School, Beech Hill Road, Sheffield SIO $2 R X$
}

(Received 21 October 1976; revised 23 November 1976)

\section{INTRODUCTION}

Little is known about the processes involved in the conversion of bacteria to the L-phase but extreme changes occur in the morphology of various species during L-phase induction. Few reports are available on the development of the L-phase of Neisseria gonorrhoeae. Studies by Dienes, Bandur \& Madoff (1964) were largely unsuccessful due to the lack of a suitable medium. However, Roberts (1966) cultured gonoccocal L-forms on medium osmotically stabilized with sucrose, and more recently Lawson \& Douglas (1973) reported successful induction and maintenance using polyvinylpyrrolidone (PVP) as an osmotic stabilizer.

We have shown that it is possible to induce gonococcal L-forms by incorporating PVP in a commercial, dehydrated medium for $N$. gonorrhoeae (Waitkins \& Geary, unpublished observations) and have now used this medium, with an agar-block impression staining technique, to trace the development of L-forms of gonococci. Lawson \& Douglas (I973) found that PVP was far more efficient than sucrose for stabilizing gonococcal L-forms; we have confirmed this, and have attempted to explain the difference by comparing the effects of these stabilizers on the morphology of the developing L-form.

\section{METHODS}

Organisms. Strains of gonococci were obtained from patients attending the Special Clinic in Sheffield, and initially isolated on selective medium. They were confirmed as $N$. gonorrhoeae by Gram-stain, oxidase reaction and sugar fermentations using the serum-free medium of Flynn \& Waitkins (1972). Colonies of the pathogenic type I (Kellogg et al., 1963) were identified using a plate microscope with suitable illumination (Jephcott \& Reyn, 197I) and subcultured on GC medium. After overnight incubation at $37^{\circ} \mathrm{C}$ in an atmosphere containing $10 \%(\mathrm{v} / \mathrm{v}) \mathrm{CO}_{2}$ the organisms were harvested and suspended in phosphate-buffered saline to a concentration of $10^{8}$ organisms $\mathrm{ml}^{-1}$. This suspension was used for the induction of L-phase colonies.

Media. Parent gonococci were cultured on Difco GC medium, plus $2 \%(\mathrm{v} / \mathrm{v})$ Defined Supplement (White \& Kellogg, I965). Selective medium used for the initial isolations was the same medium plus $\left(\mu \mathrm{g} \mathrm{ml}^{-1}\right)$ : vancomycin, $5 \cdot 0$; trimethoprim, 8.0; and colomycin, $7 \cdot 5$. The medium used for inducing L-forms was GC medium plus $10 \%(\mathrm{v} / \mathrm{v})$ horse serum, $\mathrm{I} \%$ (w/v) PVP (mol. wt 700000), and benzylpenicillin (1000 units $\mathrm{ml}^{-1}$ ). This is designated PVP medium.

A penicillin gradient technique (Roberts, 1966) was used when comparing L-phase inductions on PVP medium and sucrose medium. Sucrose medium was similar to PVP medium except it contained $10 \%(\mathrm{w} / \mathrm{v})$ sucrose instead of PVP.

\footnotetext{
* Present address: Central Public Health Laboratory, Colindale Avenue, London NW9 5HT.
} 
$L$-form induction. Thirty strains of $N$. gonorrhoeae were isolated and tested for L-form colony production by flooding the prepared suspension $(0.1 \mathrm{ml})$ on to the surface of freshly poured plates of PVP medium. The plates were incubated at $36^{\circ} \mathrm{C}$ in a moist atmosphere containing $10 \% \mathrm{CO}_{2}$ and inspected daily for L-form colonies using the plate microscope. Strains which produced L-form colonies most readily were selected and used for observation of colonial development. Induction was repeated with these strains and samples of growth were removed for staining at intervals during incubation.

Reversion of $L$-forms. Specific identification of the $L$-form colonies was made by allowing them to revert to their parental bacterial form. This was done by transferring the colonies on blocks of agar to sucrose-stabilized, penicillin-free medium. On this medium the L-form reverted to the bacterial form and grew as normal-looking gonococcal colonies which were identified by Gram-staining and fermentation reactions in the usual manner.

Staining of L-forms. The technique used for staining the developing L-forms is a modification (Waitkins \& Geary, unpublished observations) of an agar-block method for pleuropneumonia organisms (Klieneberger \& Smiles, 1942).

\section{RESULTS}

\section{$L$-form induction}

Of the 30 strains induced to the L-phase, I 2 produced colonies within 8 days of incubation. These strains were chosen for observation of colonial development on PVP medium and sucrose medium. All 12 strains grew on PVP medium, but only four strains grew on sucrose medium. Figure I shows the development of L-phase colonies on sucrose-stabilized and PVP-stabilized media.

\section{Development on PVP medium}

After 2 to $3 \mathrm{~h}$ incubation, the cocci became swollen and formed protoplast-like bodies. After $8 \mathrm{~h}$ these 'large bodies' were between 5 and $20 \mu \mathrm{m}$ in diameter, roughly spherical and had a characteristic granular appearance. The granules inside the large body varied in size and staining intensity and were unevenly distributed, being more concentrated at the periphery of the body.

During the next few hours the large body began to disintegrate and small bud-like extensions, often containing granules, developed on the surface. Some of these remained attached, others broke off and thus separated the granules from the large body. The outer edge of the large body became ragged and irregular, granules and enlarged granules were scattered around and dense granular structures 3 to $5 \mu \mathrm{m}$ in diameter and resembling the large bodies were often seen. These structures are referred to as 'secondary large bodies'.

After $24 \mathrm{~h}$ the large body disintegrated completely and became obliterated by a mass of different-sized granules and secondary large bodies. During the second day of growth clear areas or 'vacuoles' appeared; granules developed around these and radiated outwards forming the periphery of a small colony.

The colony was well established after $48 \mathrm{~h}$ and consisted of a dense central core surrounded by a vacuolated outer area. The core was composed of a compact mass of granules growing down into the agar, and the outer area consisted of granules of different sizes and large bodies spreading out on the medium surface. As the colony continued to grow, it became less granular and more vacuolated, giving it a characteristically 'foamy' appearance. Colonies reached this stage after 4 to 8 days. On further incubation they continued to increase in size but no other morphological changes occurred. 

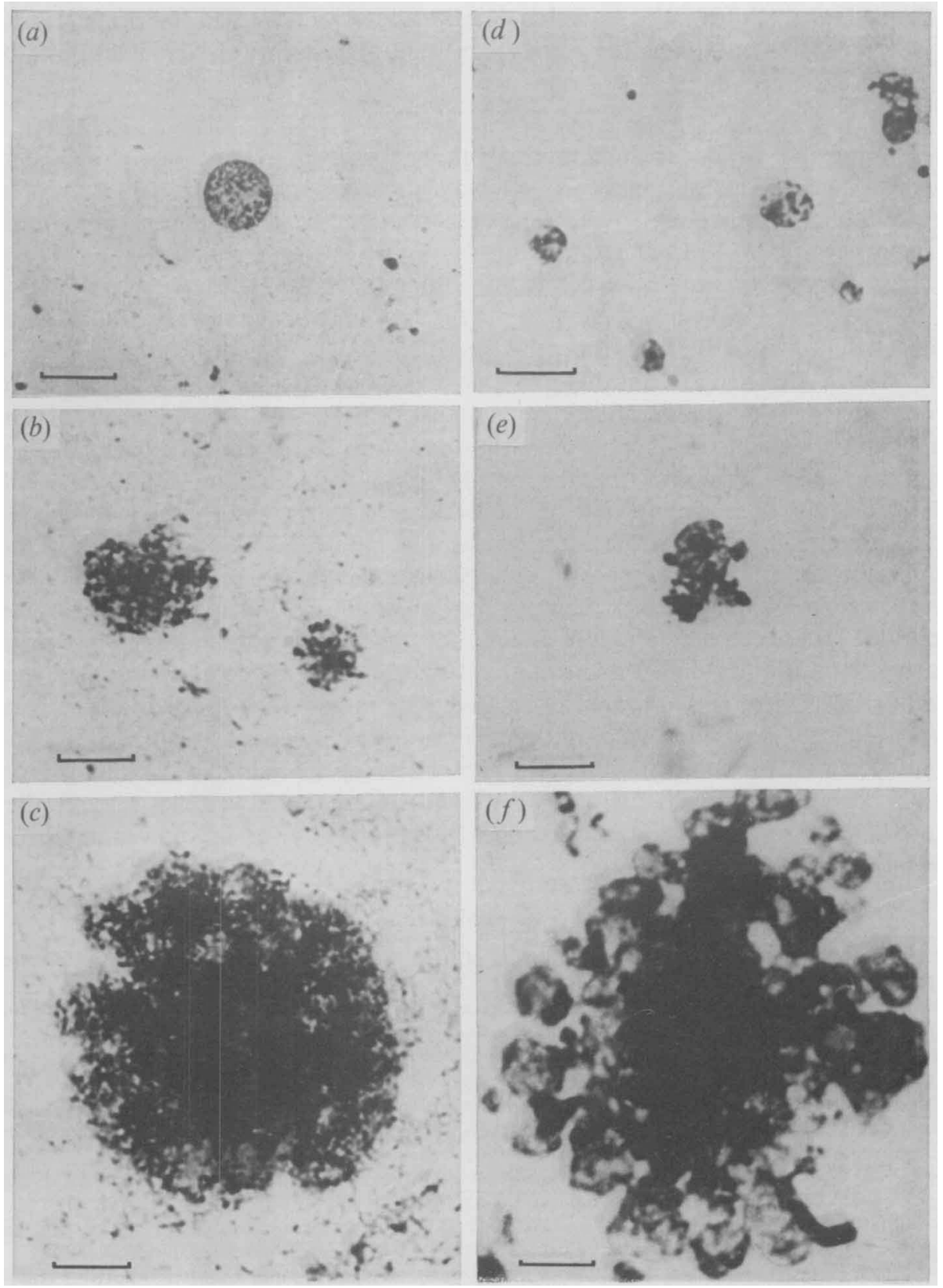

Fig. I. The development of GC L-phase colonies. $(a),(b)$ and $(c)$ are from PVP-stabilized medium at 8,16 and $24 \mathrm{~h} .(d),(e)$ and $(f)$ are from sucrose-stabilized medium at 12, 24 and $96 \mathrm{~h}$. Bar markers represent $10 \mu \mathrm{m}$.

\section{Development on sucrose medium}

Large bodies were formed after 8 to $\mathrm{I} 2 \mathrm{~h}$; these were usually smaller ( 5 to $8 \mu \mathrm{m}$ ) than those on PVP medium. Granules developed in several places on the surface of the large body and did not break off but expanded to produce secondary large bodies. The large body did not readily disintegrate, as it did on PVP medium, and after 24 to $48 \mathrm{~h}$ a small cluster of bodies 
was formed. Growth from the secondary large bodies was slow, and few granules or vacuoles developed. After 4 days the colony consisted almost entirely of intact large bodies radiating from a cental core.

\section{DISCUSSION}

Development of L-phase colonies starts with the formation of large bodies and continues with the extension and multiplication of small granular elements (Dienes \& Weinberger, I95I; Madoff \& Dienes, I958; Dienes, I967). It is not clear how the granules multiply; they have been observed to undergo various processes such as budding, fragmentation and binary fission, and are capable of developing into large bodies (Dienes, 1967; Bibel \& Lawson, 1972; Green, Heidger \& Domingue, 1974). Scanning electron micrographs show that granules are produced inside the large bodies (Bibel \& Lawson 1975); these are viable and when released give rise to typical L-phase colonies. Green et al. (1974) suggest a cycle of reproduction in which large bodies or 'mother forms' extrude granule-like 'elementary bodies' that are able to develop into new mother forms or revert to the bacterial form.

Our observations here show that the morphology of the developing GC L-phase colonies on PVP medium is similar to that of staphylococcal and streptococcal L-forms (Dienes, 1967). Granules developed from large bodies and multiplied by some means in the surrounding medium. The emergence of enlarged granules and secondary large bodies suggests that some of the granules develop into larger forms. Vacuoles are a characteristic feature of L-phase colonies, and it is thought they may be caused by the collapse or lysis of large bodies. Colonies on PVP medium often developed vacuoles. These had granules spreading from them and appeared to be secondary large bodies that had disintegrated.

When sucrose was used as an osmotic stabilizer, growth consisted mainly of large bodies, few granules were produced and vacuoles did not develop. The colonies took longer to form, possibly because the large bodies remained intact and granules were not released. Perhaps sucrose in some way suppresses spontaneous lysis of the large bodies preventing the spread and development of granules.

\section{REFERENCES}

Bibel, D. J. \& Lawson, J. W. (1972). Development of streptococcal L-form colonies. Journal of Bacteriology II2, 602-610.

Bibel, D. J. \& LAwson, J. W. (1975). Morphology and viability of large bodies of streptococcal L-forms. Infection and Immunity 12, 919-930.

DienES, L. (1967). Morphology and reproductive processes of the L-forms of bacteria. I. Streptococci and staphylococci. Journal of Bacteriology 93, 693-702.

Dienes, L. \& WeINBerger, H. J. (195I). The L-forms of bacteria. Bacteriological Reviews 15, $245^{-288 .}$

Dienes, L., Bandur, B. M. \& Madoff, S. (1964). Development of L-type growth in Neisseria gonorrhoeae cultures. Journal of Bacteriology 87, I47I-I476.

FlynN, J. \& Waitkins, S. A. (1972). A serum-free medium for testing fermentation reactions in Neisseria gonorrhoeae. Journal of Clinical Pathology 25, 525-527.

Green, M. T., Heidger, P. M., JR \& Domingue, G. (I974). Proposed reproductive cycle for a relatively stable L-phase variant of Streptococcus faecalis. Infection and Immunity ro, 91 5-927.

JePhCOTt, A. E. \& ReYN, A. (I97I). Neisseria gonorrhoeae colony variation I. Acta pathologica et microbiologica scandinavica 79, 606-614.

Kellogg, D. S., JR, Peacock, W. L., Deacon, W. E., Brown, L. \& Pirkle, C. I. (ig63). Neisseria gonorrhoeae. I. Virulence genetically linked to clonal variation. Journal of Bacteriology 85, I 274-I 279.

KLIENeberger, E. \& Smiles, J. (1942). Some new observations on the development cycle of the organism of bovine pleuropneumonia and related organisms. Journal of Hygiene 42, I IO-I 23.

Lawson, J. W. \& Douglas, J. T. (1973). Induction and reversion of the L-form of Neisseria gonorrhoeae. Canadian Journal of Microbiology 19 , $1145-1151$.

MADOFF, S. \& DiENES, L. (I958). L-forms of pneumococci. Journal of Bacteriology 76, 245-250.

ROBERTS, R. B. (1966). L-form of Neisseria gonorrhoeae. Journal of Bacteriology 92, $1609-1614$.

White, L. A. \& KellogG, D. S., JR (I965). Neisseria gonorrhoeae identification in direct smears by a fluorescent antibody counterstain method. Applied Microbiology r3, I71-1 74. 